\title{
Maximum Envelope of Lateral Resistance through Dynamic Increasing Energy Test in Piles
}

\author{
R.M. Valverde, F. Massad
}

\begin{abstract}
The traditional dynamic load test, based on the one-dimensional wave propagation theory consists in applying a sequence of constant energy blows and making measurements using deformation and acceleration sensors installed on top of the pile, as a function of time. The traditional method has evolved with the development of a numerical model that simulates the Static Load Test (SLT) of a pile dynamically tested. Another evolution was the introduction of the Dynamic Increasing Energy Test (DIET) created and proposed by Aoki (1997). The present study is an initiative to deepen the increasing energy method focusing on the definition of the maximum lateral resistance envelope, allowing the recovery of the mobilized resistance along the shaft, lost in blows prior to the maximum applied energy, especially in layers close to the top of the pile. This procedure is called the Maximum Envelope of Lateral Resistance. Two case studies are presented, in which static and dynamic tests were performed on the same pile. The application of the Maximum Envelope of Lateral Resistance, also referred to as Maximum Envelope Method, led to a definition of higher load capacities through the CAPWAP analysis, with simulated load-displacement curves with good correlations in comparison with the Static Load Tests (SLT). When performed after several rest periods, the Maximum Envelope Method allows an assessment of the "set up" development over time.
\end{abstract}

Keywords: dynamic load test, increasing energy, lateral resistance, load capacity, maximum envelope.

\section{Introduction}

The PDA ("Pile Driving Analyzer") signal of the hammer blow associated to the highest pile capacity during the dynamic load test is the one chosen to be analyzed by CAPWAP (Case Pile Wave Analysis Program). This program provides a simulation of the Static Load Test (SLT) and allows determining the mobilized shear and toe resistances as if the pile had received only that single blow since the end of its installation, without considering changes in soil properties caused by earlier blows of lower energies. However, at each applied blow, the shear and toe resistances change due to effects on the soil, particularly on those with high sensitivity. Therefore, to consider only the last blow as the one in which the maximum capacity occurs is a practice that generates simplified interpretations regarding the pile load capacity and the lateral friction along the pile shaft. The Maximum Envelope Method has the objective of evaluating the whole Dynamic Increasing Energy Test (DIET), considering the effects of the blows applied prior to the one with the maximum mobilization of static resistance. This allows recovering as much information as possible about the load capacity in a Dynamic Increasing Energy Test (DIET), including: a) a top load-settlement curve simulated through the mathematical model of Coyle and Reese (1966); and b) an assessment of the "set up" development over time in sensitive soils.

\section{Dynamic Load Test and CAPWAP}

The dynamic load test consists in applying a sequence of blows on the pile and measuring values of specific deformation and acceleration over time through force transducers and high sensitivity accelerometers. These instruments are installed at a minimum distance from the top established by standard. After applying the blows, the recorded data are sent to the PDA, which calculates the force and velocity curves of the recorded blows. The data acquired in the field can later be analyzed by CAPWAP, a computer program whose results include a simulated static analysis of the load-set curve and the distribution of resistances along the pile shaft and toe. The wave equation is solved using one variable as input (velocity or force) and computing the other variable. The results are based on the quality of the match between the curves of the calculated and the measured variables, called "Match Quality". CAPWAP allows calculating tensions and movements by dividing the pile into segments of known properties (elastic modulus and mass density). The propagations of the descending and ascending waves ("Wave down" and "Wave Up") are recorded and their superposition is done according to the wave equation, in which the ascending and descending forces are summed and the velocities are equal to their differences divided by the impedance of the pile in each segment. The displacement and velocity of each pile segment

Rafael Marin Valverde, M.Sc., PDI Engenharia e Departamento de Engenharia Civil, Escola Politécnica da Universidade de São Paulo, São Paulo, SP, Brazil. e-mail: rafael.valverde@gmail.com

Faiçal Massad, Ph.D., Full Professor, Departamento de Engenharia Civil, Escola Politécnica da Universidade de São Paulo, São Paulo, SP, Brazil. e-mail: faical.massad@usp.br.

Submitted on September 26, 2017; Final Acceptance on March 21, 2018; Discussion open until August 31, 2018

DOI: $10.28927 / \mathrm{SR} .411075$ 
are the basis for determining the soil resistance. The soil model, introduced by Smith (1960), consists in an elastoplastic spring and a linear dashpot. The total static load capacity is the sum of the static resistances of the shaft and pile toe segments.

Figure 1 illustrates the association between the basic static resistance and the pile shaft displacement. In the loading phase, as a pile segment moves downward, the static resistance increases linearly over a quake distance $\mathrm{q}_{\mathrm{s}}$ up to the maximum shaft resistance value $R_{u}$, and then it remains constant until the maximum displacement $u_{\mathrm{px}}$ on this element is reached. Next is the unloading phase, with a slope defined by the "unloading quake" $\mathrm{q}_{\mathrm{u}}$ up to a negative ultimate resistance level $R_{n u}$, which is the minimum limit defined by the product of $R_{u}$ and an unloading multiplier $U_{n}$ (Rausche et al., 2010).

For the static pile toe resistance, there is a similar association except for the unloading phase, in which the toe resistance is zero $\left(\mathrm{U}_{\mathrm{n}}\right.$ value is 0$)$. As the pile toe moves downward, the resistance may eventually remain zero due to some existing gap ("Resistance toe gap"), represented by $\mathrm{t}_{\mathrm{g}}$ and then increases linearly over a quake distance $\mathrm{q}_{\mathrm{t}}$ ("loading toe quake") until it reaches the maximum toe resistance $\mathrm{R}_{\mathrm{w}}$, and remains constant up to a maximum displacement $u_{t}($ Fig 2). For total toe resistance activation, the pile toe displacement must be greater than the sum of the quake $\mathrm{q}_{\mathrm{t}}$ and the toe gap $\mathrm{t}_{\mathrm{g}}$.

This model even allows considering a soil mass embedding on the shaft or pile toe. In order to be able to match certain signals, it was necessary to include an extension of the soil model called "Radiation Damping", necessary in cases when displacements are small and the soil practically moves with the pile. An example is a pile partially embedded on hard rock. As the pile exerts compression forces

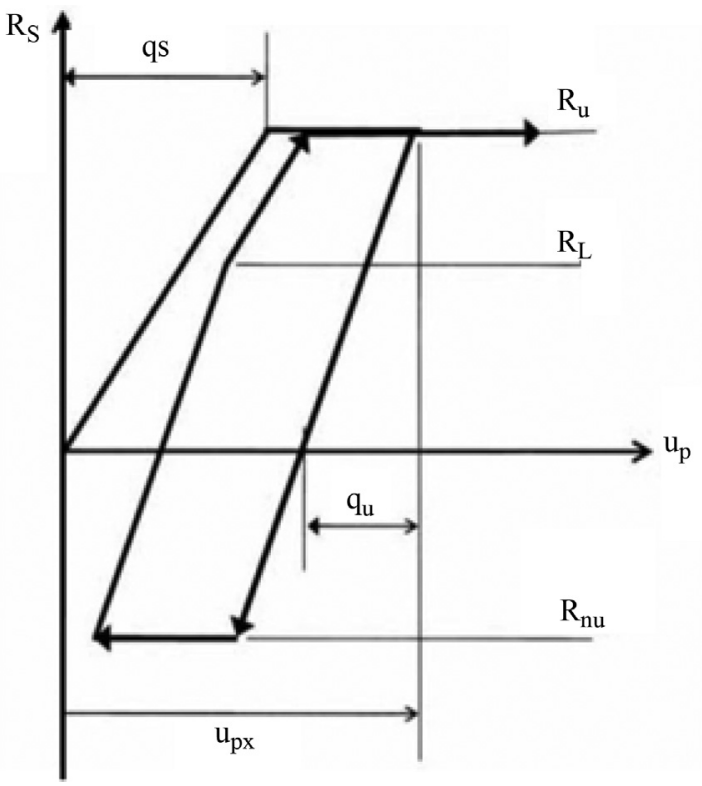

Figure 1 - Static shaft resistance-displacement - CAPWAP soil model (Pile Dynamics 2006).

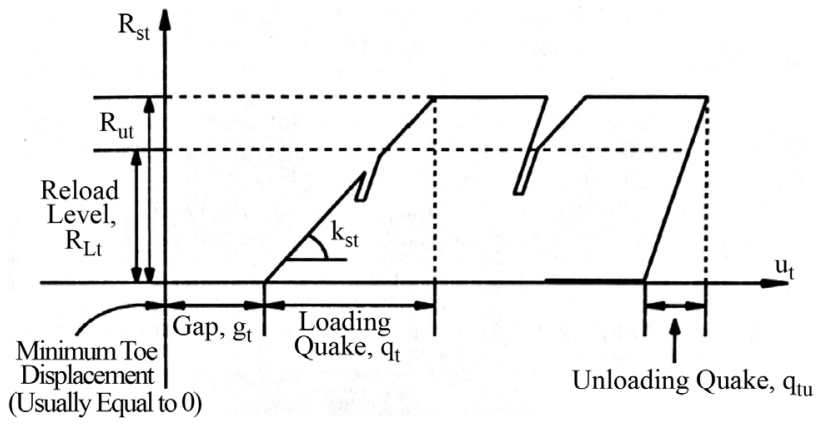

Figure 2 - Toe static resistance-displacement - CAPWAP soil model (Pile Dynamics 2006).

against the rock, a wave is generated in the rock and the soil resistance appears to be a function of the velocity rather than the displacement (Pile Dynamics, 2006).

The balance of forces and displacements at the top is computed by ignoring the viscous effects of the soil (Rausche et al., 1994). The results of the CAPWAP signal matching process are primarily ultimate resistance values and quakes (and therefore soil stiffness). Together with the pile stiffness, CAPWAP produces a simulated static loadset curve. Such procedure yields important limitations that should be considered:

(i) the simulated static load-set curve represents a load test that was performed during a fraction of a second; for that reason, the result cannot include displacements caused by consolidation of soil layers below or around the pile;

(ii) the calculated static load-set curve refers to the time of the dynamic testing and may differ from the Static Load Test (SLT) curve with longer waiting time; and

(iii) for concrete piles, the elastic modulus used in the calculation of the static load-settlement curve is the same as that determined by the PDA. Static elastic moduli are generally lower than the dynamic moduli and the static analysis options allow for an input of pile modulus reduction factor, as stated in the CAPWAP manual (Pile Dynamics, 2006).

\section{Maximum Envelope Method}

The main objective of the Maximum Envelope Method is to analyze all the blows applied during the Dynamic Increasing Energy Test (DIET). Rausche et al. (1994) state that the distribution of ultimate shaft resistance forces of all segments can be directly determined from the record portion between the time of impact and the time of the first wave return. This procedure is applied to all blows of the DIET allowing to calculate the maximum envelope of the shaft resistance distribution and, additionally, the maximum toe resistance. These results, together with soil profile, make it possible to estimate elasto-plastic load transfer functions for each soil layer, also known as q-z and t-z functions, as shown in Figs. 1 and 2. In this paper only the loading phase will be considered. 
The authors applied the Coyle-Reese method to simulate the static load-set curve using these elasto-plastic load transfer functions, in order to validate the results obtained through the Maximum Envelope Method. The validation is accomplished comparing the resulting curve with the Static Load Test (SLT) curve. In the Coyle-Reese method the pile is divided into segments with their respective load transfer functions. Its application initiates from the last element of the pile assuming that the pile toe has moved a small displacement $y_{t}$ downward. Through the pile toe load transfer function, the toe resistance $Q_{p}$ is determined. Then, forces and displacements of upper segments are calculated iteratively up to the top using the lateral load transfer functions and considering the elastic shortening of the pile together with the balance of acting forces, in order to obtain one point of the load-settlement curve. This process is iteratively repeated, assuming different pile toe displacements $y_{t}$, to obtain several points of the load-set curve until the maximum lateral friction (determined by the Maximum Envelope Method) of all soil segments is reached.

The number of segments in the Coyle-Reese method should be the same or greater than the number of soil layers determined by local geotechnical tests, like the Standard Penetration Test (SPT). Each blow applied during the Dynamic Increasing Energy Test (DIET) indicates different values of lateral resistance and, therefore, different skin friction $\mathrm{f}_{\mathrm{s}}$ and quake $\mathrm{q}_{\mathrm{s}}$ values. According to Fig. 3, the max- imum skin friction value $\mathrm{f}_{\text {max }}$ of each soil layer is the average of the greatest $\mathrm{f}_{\mathrm{s}}$ values calculated through the CAPWAP, considering all applied blows during the DIET, in accordance with the Maximum Envelope Method, described above.

\section{First Case: Port Terminal - Santos, SP - Brazil}

\subsection{Pile and subsoil profiles}

The first case studied refers to a pile (EC1304) of a terminal port at the Santos Coastal Plain ("Baixada Santista"), Brazil. It was a precast concrete pile, circular, with an outer diameter of $80 \mathrm{~cm}$, a wall thickness of $15 \mathrm{~cm}$ and a nominal cross-sectional area of $3062.05 \mathrm{~cm} 2$. The pile had a total length of $52.0 \mathrm{~m}$, in which $43.4 \mathrm{~m}$ have penetrated in the soil. These and other characteristics are shown on Table 1 .

The pile was driven offshore, on May 29th, 2012, using a $160 \mathrm{kN}$ Junttan HHK hydraulic hammer. During the initial $20 \mathrm{~m}$, the pile penetrated the soil with an approximately constant rate of $50 \mathrm{~cm}$ for every 20 blows applied and, from this point on, with the same number of blows, the penetration reduced to $20 \mathrm{~cm}$ until reaching the final depth with $43.4 \mathrm{~m}$ of its length.

The soil profile was determined from several field tests $6 \mathrm{~m}$ below sea water level. The subsoil is composed

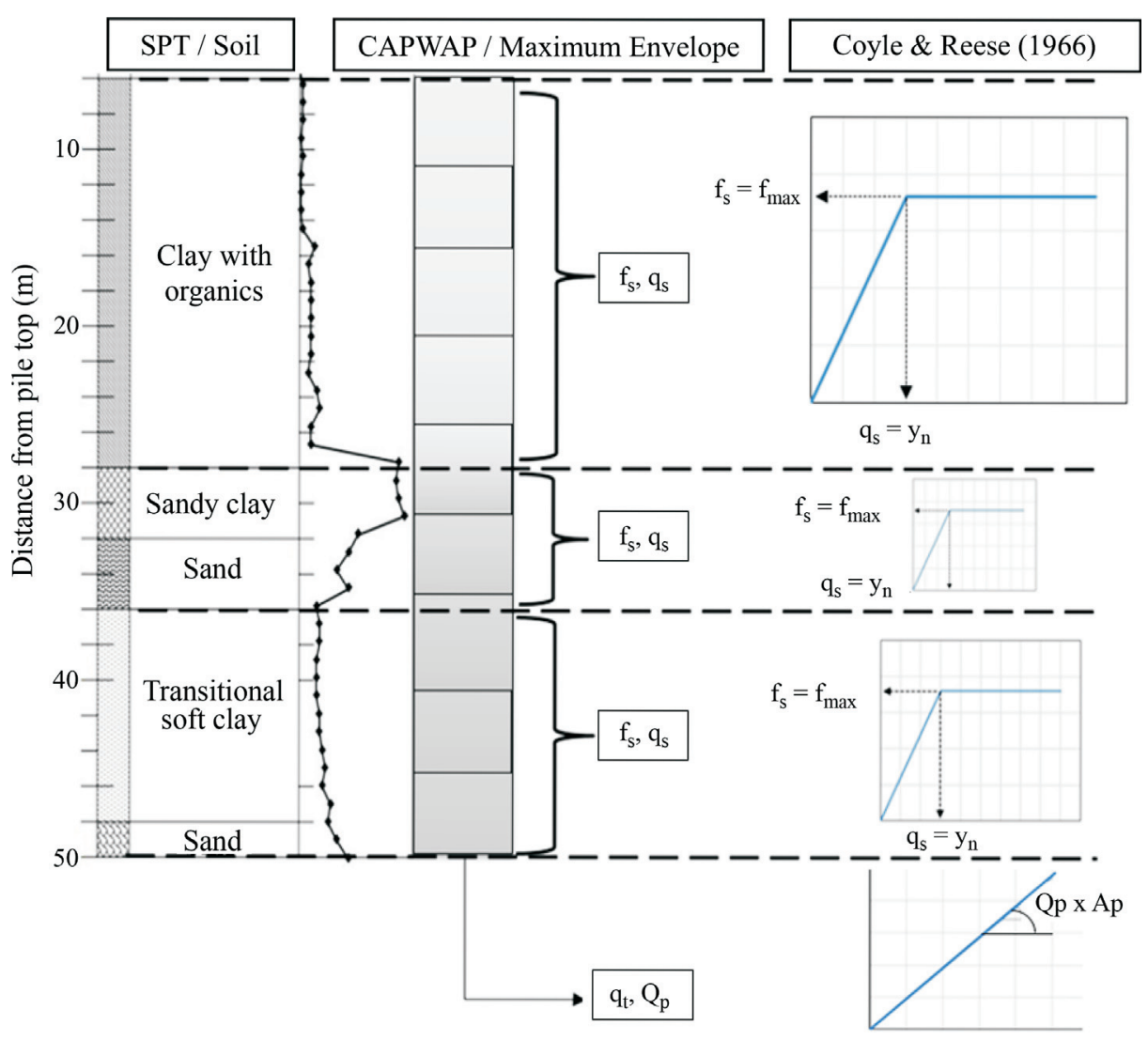

Figure 3 - Relationship between soil profile, maximum envelope results and Coyle-Reese load transfer functions. 
Table 1 - EC1304 pile profile and PDA data.

\begin{tabular}{|c|c|c|c|c|c|c|c|}
\hline \multirow[t]{2}{*}{ Pile name } & \multicolumn{2}{|c|}{ Diameter } & \multicolumn{3}{|c|}{ Length } & \multirow{2}{*}{$\begin{array}{c}\text { Wave speed } \\
(\mathrm{m} / \mathrm{s})\end{array}$} & \multirow{2}{*}{$\begin{array}{c}\text { Dynamic modulus } \\
\text { (GPa) }\end{array}$} \\
\hline & Outside $(\mathrm{cm})$ & Inside $(\mathrm{cm})$ & Total (m) & Below sensors (m) & Embedded (m) & & \\
\hline EC1304 & 80.0 & 50.0 & 52.0 & 50.8 & 43.40 & 3700 & 34.2 \\
\hline
\end{tabular}

initially by a $20 \mathrm{~m}$ thick very soft organic marine clay, locally known as SFL Clay (Fluvio Lagunar Sediment), which is generally slightly overconsolidated (OCR 1.1 to 1.5), followed by a medium to compact clayey sand (SPT ranging from 7 to 33 blows), about $8 \mathrm{~m}$ thick. These soils overlie $4 \mathrm{~m}$ of an overconsolidated clay, with OCR greater than 2.5 due to a great sea level lowering during the last glaciation, known locally as Transitional Clay (AT), with SPT higher than 5. Finally, at depth greater than $32 \mathrm{~m}$ below seabed occur thin to thick layers of compact sand, with SPT of the order of 10. More detailed information about the origin and composition of these soils can be found in Massad (2009).

\subsection{Static Load Test (SLT)}

The Static Load Test (SLT) was performed on August 7 and 8, 2012, about 70 days after pile installation, using a set of pumps, hydraulic jack and pressure gauge supported on a block of concrete and 4 reaction piles. Known as Mixed Maintained Load, the test consisted of slow applications of load increments during the loading phase and quick unload during the unloading phase, according to NBR 12131 (2006). The maximum load and displacement in the Static Load Test (SLT) were $8407 \mathrm{kN}$ and $34 \mathrm{~mm}$, respectively, without indication of failure and the permanent set was 6 mm, as shown in Fig. 4.

\subsection{Dynamic Increasing Energy Test (DIET) and CAPWAP}

Pile EC1304 was dynamically tested on June 6, 2012, therefore about 8 days after its installation. Blows with the following hammer drop heights were applied: 20; 40; 60; $80 ; 100 ; 120 ; 120 ; 120$ and $120 \mathrm{~cm}$. The last applied blow corresponding to the highest mobilized resistance was used for the first CAPWAP analysis. Table 2 provides some of the numerical results obtained from the "best match quality" of CAPWAP analysis.

Figure 4 shows visually an excellent correlation between the curve simulated by the CAPWAP and the curve obtained from Static Load Test (SLT).

Table 2 - CAPWAP analysis results - Pile EC1304.

\subsection{Maximum envelope of lateral resistance - EC1304}

Figure 5 shows the lateral resistance in pile segments distributed along depth given by the CAPWAP for each applied blow. It is possible to notice that in the first half of the pile the maximum values of lateral friction are associated with lower energy blows. In the lower half, such maximum lateral resistances are reached with higher energy blows.

After each new applied blow, the soil undergoes changes and loses part of the resistance recovered during the "set up". Figure 5 allows to compare the lateral resistance of the last blow $\left(120^{(3)} \mathrm{cm}\right)$ with the Maximum Envelope, highlighted in dashed line. The envelope of lateral resistance of EC1304 pile allows some considerations regarding lateral resistance: (i) blows with hammer drops of $20 \mathrm{~cm}$ to $80 \mathrm{~cm}$ indicate greater static lateral resistances up to approximately $24 \mathrm{~m}$; (ii) the first $20 \mathrm{~m}$ show a gradual reduction of lateral resistance as the hammer drop heights increase, up to a minimum limit of lateral resistance; (iii) the last blow $\left(120^{(3)} \mathrm{cm}\right)$, represented with a full black line, is at the minimum limit of the mobilized lateral resistance in the upper segments, until approximately $22 \mathrm{~m}$.

Using the dashed line of Fig. 5, i.e., the Maximum Envelope of Lateral Resistance, associated with the highest mobilized toe resistance (blow $120^{(3)} \mathrm{cm}$ ), the total pile capacity was estimated as $10085 \mathrm{kN}$. Figure 6 shows the curves simulated by CAPWAP considering as the starting

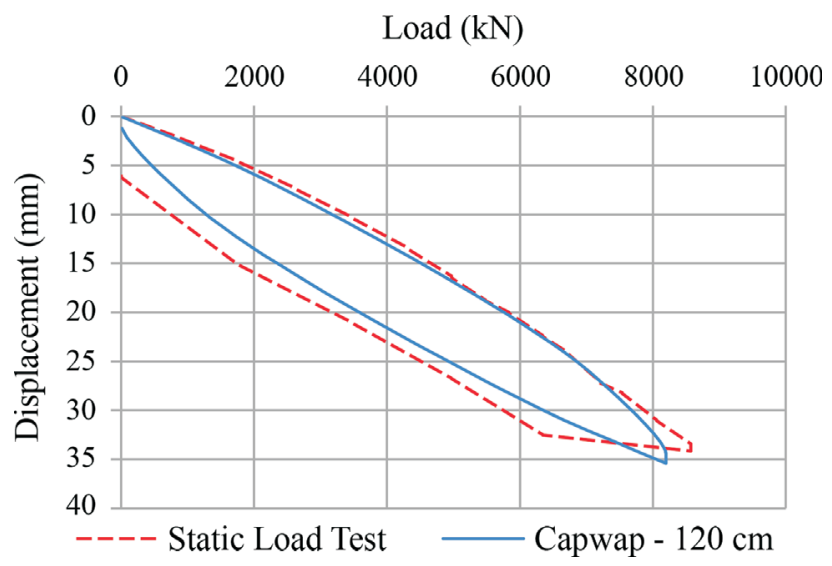

Figure 4 - Simulated CAPWAP and Static Load Test curves blow $120 \mathrm{~cm}$ - EC1304.

\begin{tabular}{|c|c|c|c|c|c|c|c|}
\hline \multirow[t]{2}{*}{ Pile name } & \multirow{2}{*}{$\begin{array}{c}\text { Total capacity } \\
(\mathrm{kN})\end{array}$} & \multicolumn{2}{|c|}{ Lateral resistance } & \multicolumn{2}{|c|}{ Toe resistance } & \multirow{2}{*}{$\begin{array}{c}\text { Shaft quake } \\
(\mathrm{mm})\end{array}$} & \multirow{2}{*}{$\begin{array}{c}\text { Toe quake } \\
\text { (mm) }\end{array}$} \\
\hline & & $(\mathrm{kN})$ & $(\%)$ & $(\mathrm{kN})$ & $(\%)$ & & \\
\hline EC1304 & 8044 & 6206 & 77 & 1838 & 23 & 2.31 & 3.32 \\
\hline
\end{tabular}




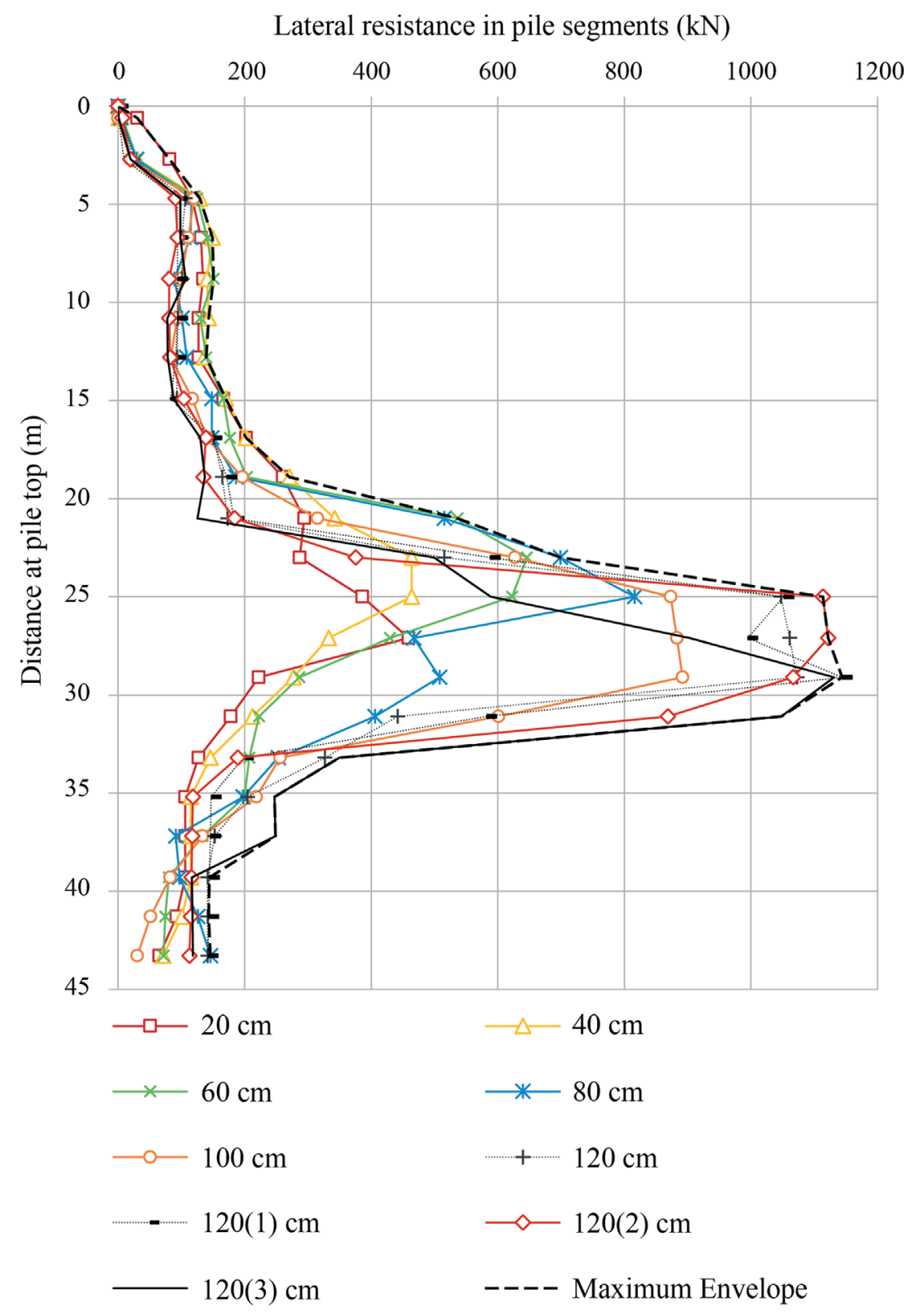

Figure 5 - Lateral resistance distribution - EC1304.

point of each applied blow the final point of the precedent blow, like a cyclic monotonic test. The set of simulated CAPWAP curves maintain a good visual correlation with the Static Load Test (SLT). It is possible to notice that there was no evidence of failure, as emphasized previously.

\subsection{Coyle-Reese method using the last applied blow $\left(120^{(3)} \mathrm{cm}\right)$}

For the application of the Coyle-Reese method to the last blow $\left(120^{(3)} \mathrm{cm}\right)$ using CAPWAP results, the part of the pile embedded in the soil was divided into 5 segments, the same number of layers identified in the soil profile, as shown in Table 3 . In this table, the shaft quake $\mathrm{q}_{\mathrm{s}}$ was assumed constant indicating the full activation of lateral resistance throughout the pile length. Furthermore, the toe quake was figured out as $3.3 \mathrm{~mm}$ with $1838 \mathrm{kN}$ of toe resistance. The static elastic modulus of the pile was figured out as $27.8 \mathrm{GPa}$, i.e., $86 \%$ of the dynamic modulus (see Table 1), according to Lydon and Balendran (1986) empirical relation. The last column of Table 3 shows the "elastic" parameter B of each load transfer function. The pile length above ground was $8.6 \mathrm{~m}$.

The result of Coyle-Reese method is shown in Fig. 7. The total capacity by the Coyle-Reese method was estimated at $8029 \mathrm{kN}$ with $38 \mathrm{~mm}$ of displacement. The loadset curve was adjusted considering the elastic shortening of the part of the pile above the sea bed in order to simulate the same conditions of the Static Load Test (SLT), which added $10 \mathrm{~mm}$ in the last point of the curve. The CoyleReese curve of Fig. 7 is close to the curves of the static load 


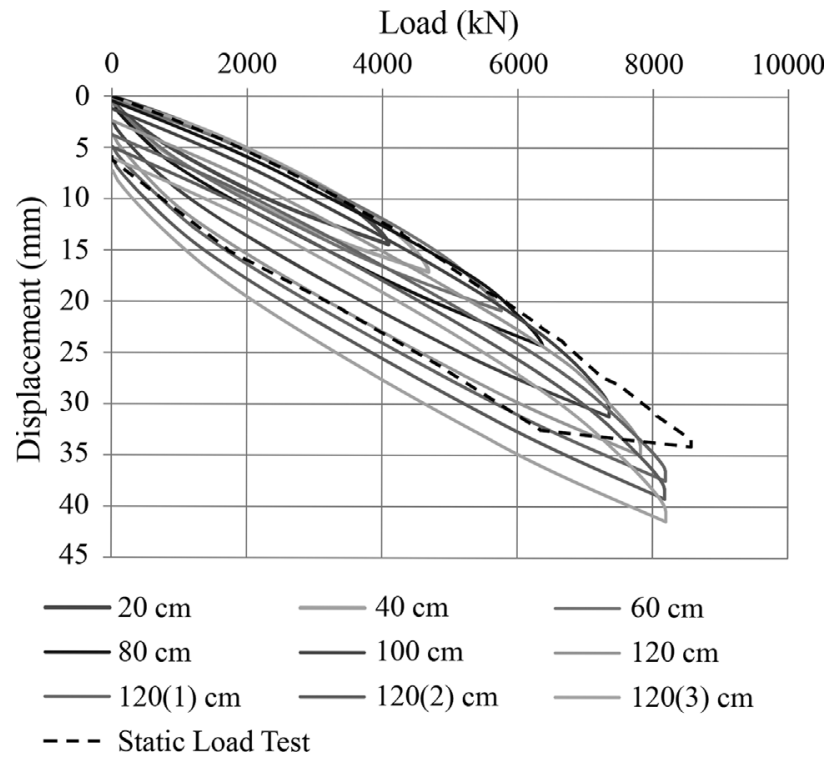

Figure 6 - Simulated static curves from CAPWAP vs Static Load Test - EC1304.

test and the simulated static curve from CAPWAP, at least up to the $4000 \mathrm{kN}$ load.

\subsection{Coyle-Reese method using maximum envelope re- sults}

For this new Coyle-Reese application, the mean lateral friction of each soil layer was determined using the dashed line of Fig. 5 and is shown in Table 4, together with the values of the mean shaft quakes. The result is presented in Fig. 8, which reveals excellent correlation between the Coyle-Reese simulated curve using Maximum Envelope results and the Static Load Test (SLT). In addition, the total capacity from the Coyle-Reese curve was $9863 \mathrm{kN}$ with $45 \mathrm{~mm}$ of displacement. This total capacity is close to

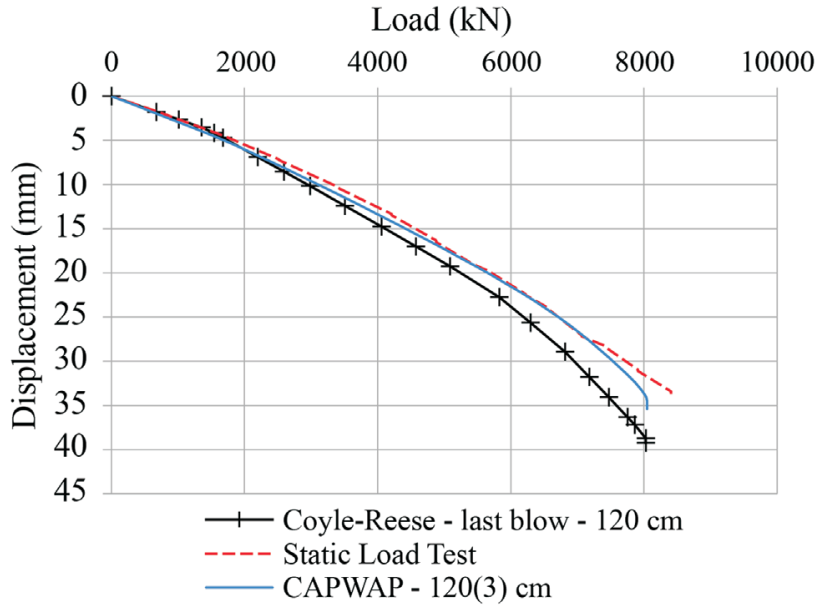

Figure 7 - Simulated load-set curves vs. Static Load Test EC1304.

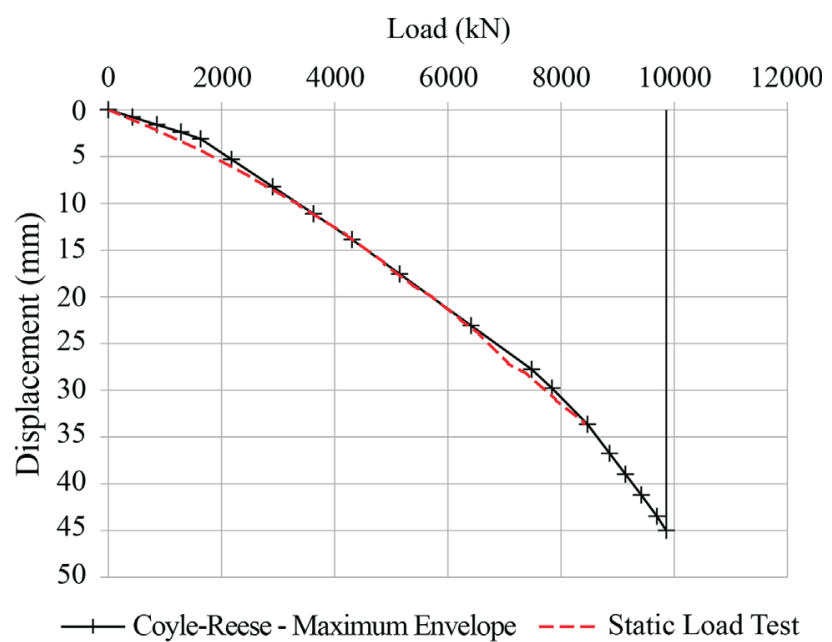

Figure 8 - Simulated load-set curve vs. Static Load Test - EC 1304.

Table 3 - Input data for the Coyle-Reese method - last applied blow $\left(120^{(3)} \mathrm{cm}\right)$ - EC1304.

\begin{tabular}{lccccc}
\hline No. & Soil Layer & $\Delta \mathrm{H}(\mathrm{m})$ & $\mathrm{f}_{\max }(\mathrm{kPa})$ & $\mathrm{y}_{\mathrm{n}}(\mathrm{mm})$ & $\mathrm{B}=\mathrm{f}_{\max } / \mathrm{y}_{\mathrm{n}}(\mathrm{kPa} / \mathrm{mm})$ \\
\hline 1 & SFL Clay & 20 & 17.7 & 2.308 & 7.7 \\
2 & Clayey sand & 4 & 60.0 & 2.308 & 26.0 \\
3 & Transitional clay & 8 & 176.3 & 2.308 & 76.4 \\
4 & Medium sand & 10 & 41.5 & 2.308 & 18.0 \\
5 & Compact sand & 2 & 22.7 & 2.308 & 9.8 \\
\hline
\end{tabular}

Table 4 - Input data for the Coyle-Reese method - Maximum Envelope - EC1304.

\begin{tabular}{lccccc}
\hline No. & Soil layer & $\Delta \mathrm{H}(\mathrm{m})$ & $\mathrm{f}_{\max }(\mathrm{kPa})$ & $\mathrm{y}_{\mathrm{n}}(\mathrm{mm})$ & $\mathrm{B}=\mathrm{f}_{\max } / \mathrm{y}_{\mathrm{n}}(\mathrm{kPa} / \mathrm{mm})$ \\
\hline 1 & SFL Clay & 20 & 28.8 & 1.25 & 23.1 \\
2 & Clayey sand & 4 & 116.4 & 1.7 & 68.5 \\
3 & Transitional clay & 8 & 208.8 & 2.46 & 84.9 \\
4 & Medium sand & 10 & 42.3 & 1.75 & 24.2 \\
5 & Compact sand & 2 & 27.9 & 0.234 & 119.3 \\
\hline
\end{tabular}


$10085 \mathrm{kN}$, estimated in section 4.4, using the Maximum Envelope of Lateral Resistance.

In order to show the difference of the unit skin friction values of the SFL Clay layer between the CAPWAP of the last blow and the Maximum Envelope method, Fig. 9 shows the average load transfer function calculated with CAPWAP results of all applied blows during the dynamic load test. The peak of the curve, with unit skin friction of $28.8 \mathrm{kPa}$ and displacement of $1.25 \mathrm{~mm}$, corresponds to the values of $\mathrm{f}_{\max }$ and $\mathrm{y}_{\mathrm{n}}$ of Table 4. For displacements above roughly $2.3 \mathrm{~mm}$, the curve tends to a residual value indicating a condition close to a remolded soil; this value was used in the Coyle-Reese method for the last applied blow $\left(120^{(3)} \mathrm{cm}\right)$.

\subsection{Summary of static resistance results - EC1304}

Table 5 summarizes the results obtained for the first case, related to the static resistances. Notice that the toe re-

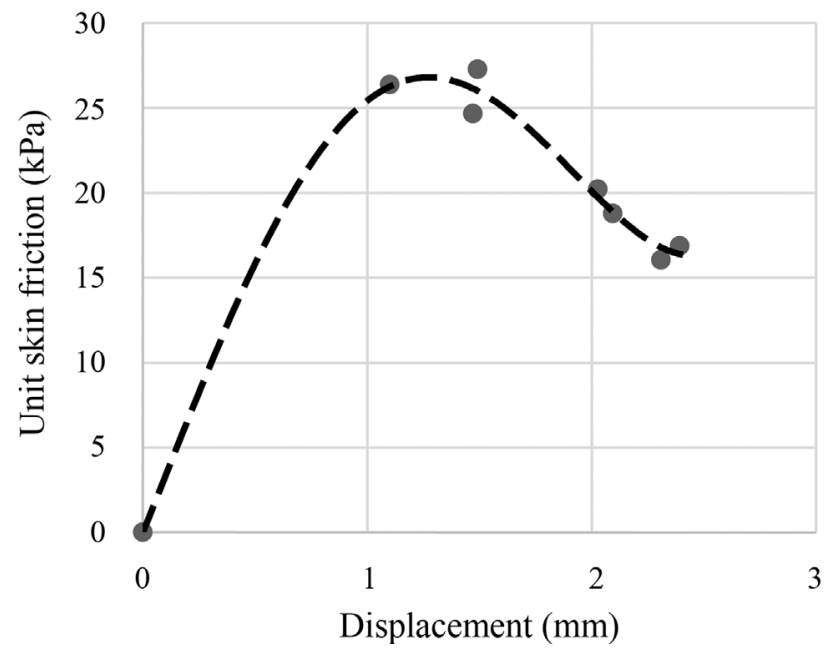

Figure 9 - Average load transfer function for the SFL Clay from Max. Envelope Method.

Table 5 - Final results - EC1304.

\begin{tabular}{|c|c|c|c|}
\hline \multirow[t]{2}{*}{ Test/method } & \multicolumn{3}{|c|}{ Static resistance $(\mathrm{kN})$} \\
\hline & Shaft & Toe & Total \\
\hline Static Load Test (SLT) & - & - & 8407 \\
\hline CAPWAP - $120^{(3)}$ & 6206 & $1838^{*}$ & 8044 \\
\hline Maximum envelope & 8247 & $1838^{*}$ & 10085 \\
\hline Coyle-Reese - $120^{(3)}$ & 6191 & $1838^{*}$ & 8029 \\
\hline Coyle-Reese - maximum envelope & 8025 & $1838^{*}$ & 9863 \\
\hline
\end{tabular}

sistance has the same value, determined by CAPWAP applied to the last blow $\left(120^{(3)} \mathrm{cm}\right)$. The total static resistances from this single blow (CAPWAP $120^{(3)}$ ) and from the Static

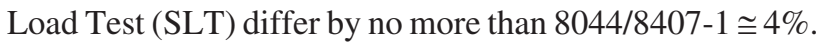
Moreover, compared with CAPWAP $120^{(3)} \mathrm{cm}$, the Maximum Envelope Method allows estimating a lateral resistance increment of $8247-6206=2041 \mathrm{kN}$.

\section{Second Case: Steel Tube Pile in Port - Santos, SP - Brazil}

\subsection{Pile properties}

The second case refers to a test pile for the construction of a pier in the Piaçaguera Chanel, close to Cubatão City in the Santos Coastal Plain ("Baixada Santista"), Brazil. The tests were performed on a steel tube driven pile, with external diameter of $91.4 \mathrm{~cm}$ and wall thickness equal to $16 \mathrm{~mm}$, resulting in a section steel area of $451.4 \mathrm{~cm}^{2}$. The pile (PC01) was submitted to Static Load Test (SLT) and to Dynamic Increasing Energy Tests (DIET) and its characteristics are detailed in Table 6.

The pile was installed on February 11, 2015, using a $90 \mathrm{kN}$ Junttan HHK hydraulic hammer. Dynamic load tests were performed after the end of driving (EOD) and after several rest periods: $3 \mathrm{~h}, 6 \mathrm{~h}, 24 \mathrm{~h}, 48 \mathrm{~h}$ and $216 \mathrm{~h}$ (9 days). The objective was to analyze the "set up" effect of the soil and to estimate the long term lateral resistance, applying the Maximum Envelope Method. The Static Load Test was performed three months after the DIETs, using the Slow Maintained Load procedure in accordance to NBR 12131 (ABNT 2006).

The subsoil profile is composed initially by a $6 \mathrm{~m}$ fill layer of clayey sand $\mathrm{m}$ (SPT 1 to 10), followed by (i) a soft layer of the SFL Clay (18 m thick and SPT 2 to 4 ), and (ii) $6 \mathrm{~m}$ of fine to coarse sand, with gravel, SPT ranging from 15 to 30 . Below about $30 \mathrm{~m}$ there is a layer of fine to coarse clayey sand, $8 \mathrm{~m}$ thick (SPT 12 to 30), overlying gneiss. The SFL Clay layer may be subdivided in two sublayers, half with $\mathrm{SPT} \cong 2$ and half with $\mathrm{SPT} \cong 4$.

\subsection{Dynamic Increasing Energy Tests (DIET) and CAPWAP - $216 \mathrm{~h}$}

Dynamic Increasing Energy Tests (DIETs) were performed at the end of driving and in all "set up" periods. Blows with the following hammer drop heights were applied: 20;40;60;80;100 and $120 \mathrm{~cm}$. The results of the CAPWAP analysis of the last blow after the $216 \mathrm{~h}$ "set up" time are shown in Table 7 and in Fig. 10.

Table 6 - PC01 pile profile and PDA data.

\begin{tabular}{|c|c|c|c|c|c|c|c|}
\hline \multirow[t]{2}{*}{ Pile name } & \multicolumn{2}{|c|}{ Diameter } & \multicolumn{3}{|c|}{ Length } & \multirow{2}{*}{$\begin{array}{c}\text { Wave speed } \\
(\mathrm{m} / \mathrm{s})\end{array}$} & \multirow{2}{*}{$\begin{array}{c}\text { Dynamic modulus } \\
(\mathrm{GPa})\end{array}$} \\
\hline & Outside $(\mathrm{cm})$ & Inside $(\mathrm{cm})$ & Total (m) & Below sensors (m) & Embedded (m) & & \\
\hline $\mathrm{PC} 01$ & 91.4 & 88.2 & 40.1 & 36.14 & 33.30 & 5123 & 210.9 \\
\hline
\end{tabular}


This test was performed on 02/20/2015, three months before the Static Load Test (SLT), which justifies the difference between the maximum displacements shown in Fig. 10: $28 \mathrm{~mm}$ in the Static Load Test (SLT) against $35 \mathrm{~mm}$ in the dynamic test.

\subsection{Maximum envelope of lateral resistance - $216 \mathrm{~h}$}

The Maximum Envelope result for the $216 \mathrm{~h}$ "set up" period is shown in dashed line in Fig. 11, together with the distribution of lateral resistance in pile segments along depth for various hammer drop heights. It can be noticed the same behavior of the first case, i.e., as the applied energy increases, lower values of lateral static resistances are gradually mobilized in segments of the pile close the top, in contrast to higher values in segments close the pile toe.

Table 8 summarizes the static resistances and reveals an increase of $5252 / 4647-1 \cong 13 \%$ in the lateral resistance estimated with the Maximum Envelope Method compared to the single $120 \mathrm{~cm}$ CAPWAP analysis. Note that, main-

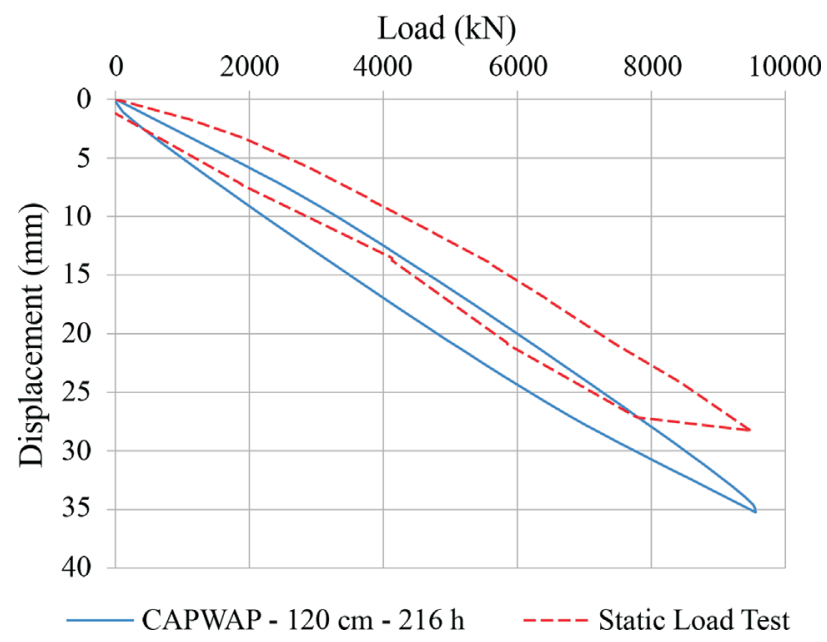

Figure 10 - Simulated CAPWAP and Static Load Test curves 216 h "set up" - PC01. taining the same value for the pile toe, this amount drops to $10164 / 9559-1 \cong 6 \%$ for the total static resistance.

Figure 12 allows comparing the Maximum Envelope with the lateral resistance distributions obtained by the CAPWAP on the last blow $(120 \mathrm{~cm})$ at the end of driving and after $216 \mathrm{~h}$ rest period. At the end of the driving, a lateral resistance of $1381 \mathrm{kN}$ was estimated by the CAPWAP. Using the data shown in Table 8, it may be concluded that the lateral resistance increased $4647 / 1381-1 \cong 336 \%$ for the last blow $(120 \mathrm{~cm})$ after the 216 -h period ( 9 days) compared to $5252 / 1381$ - $1 \cong 380 \%$ related to the Maximum Envelope.

\section{4. "Set up" evaluation using the Maximum Envelope of Lateral Resistance - PC01}

Dynamic load test results at all "set up" periods, presented in Table 9, indicate lateral and total resistance gains over time. This is also evident with the Maximum Envelope results.

The decreasing toe resistance values over time, observed in Table 9, indicate that the pile toe was not fully mobilized due to the lateral resistances increase along the pile shaft. Based on these results, Figs. 13 and 14 show variations of the $\mathrm{Q} / \mathrm{Q}_{0}$ ratio for the lateral resistance and for the total capacity over time. In this relation, $\mathrm{Q}$ and $\mathrm{Q}_{0}$ are lateral resistance (Fig. 13) or load capacity (Fig. 14) after a certain period of rest and at the end of driving (EOD), respectively.

It is possible to notice that the lateral resistance increases significantly during the first $48 \mathrm{~h}$ and, after that, the increments are smaller and practically linear. An important factor to consider when evaluating the "set up" is the activation of all skin frictions during the dynamic test. Therefore, it is necessary to evaluate the shaft quake $\mathrm{q}_{\mathrm{s}}$ of the last blow $(120 \mathrm{~cm})$ for each period of rest. If the result of the CAPWAP shows that the shaft quake does not remain constant and that from a certain depth it decreases, it may be

Table 7 - CAPWAP Analysis results - PC01-120 cm blow and $216 \mathrm{~h}$ "set up" time.

\begin{tabular}{|c|c|c|c|c|c|c|c|}
\hline \multirow[t]{2}{*}{ Pile name } & \multirow{2}{*}{$\begin{array}{c}\text { Total capacity } \\
(\mathrm{kN})\end{array}$} & \multicolumn{2}{|c|}{ Lateral resistance } & \multicolumn{2}{|c|}{ Toe resistance } & \multirow{2}{*}{$\begin{array}{c}\text { Shaft quake } \\
\text { (mm) }\end{array}$} & \multirow{2}{*}{$\begin{array}{c}\text { Toe quake } \\
\text { (mm) }\end{array}$} \\
\hline & & $(\mathrm{kN})$ & $(\%)$ & $(\mathrm{kN})$ & $(\%)$ & & \\
\hline PC01 & 9559 & 4647 & 48 & 4.912 & 52 & 5.73 & 1.75 \\
\hline
\end{tabular}

Table 8 - Distribution of resistance along the pile - PC01-216 h "set up" time.

\begin{tabular}{|c|c|c|c|c|c|c|c|}
\hline \multirow{2}{*}{$\begin{array}{l}\text { Static } \\
\text { resistances }\end{array}$} & \multicolumn{6}{|c|}{ Hammer drop heights $(\mathrm{cm})$} & \multirow{2}{*}{$\begin{array}{c}\text { Maximum } \\
\text { envelope }\end{array}$} \\
\hline & 20 & 40 & 60 & 80 & 100 & 120 & \\
\hline Lateral $(\mathrm{kN})$ & 3063 & 3644 & 3867 & 3993 & 3938 & 4647 & 5252 \\
\hline Toe $(\mathrm{kN})$ & 753 & 2390 & 2528 & 4085 & 4530 & 4912 & 4912 \\
\hline Total $(\mathrm{kN})$ & 3816 & 6034 & 6395 & 8078 & 8468 & 9559 & 10164 \\
\hline
\end{tabular}




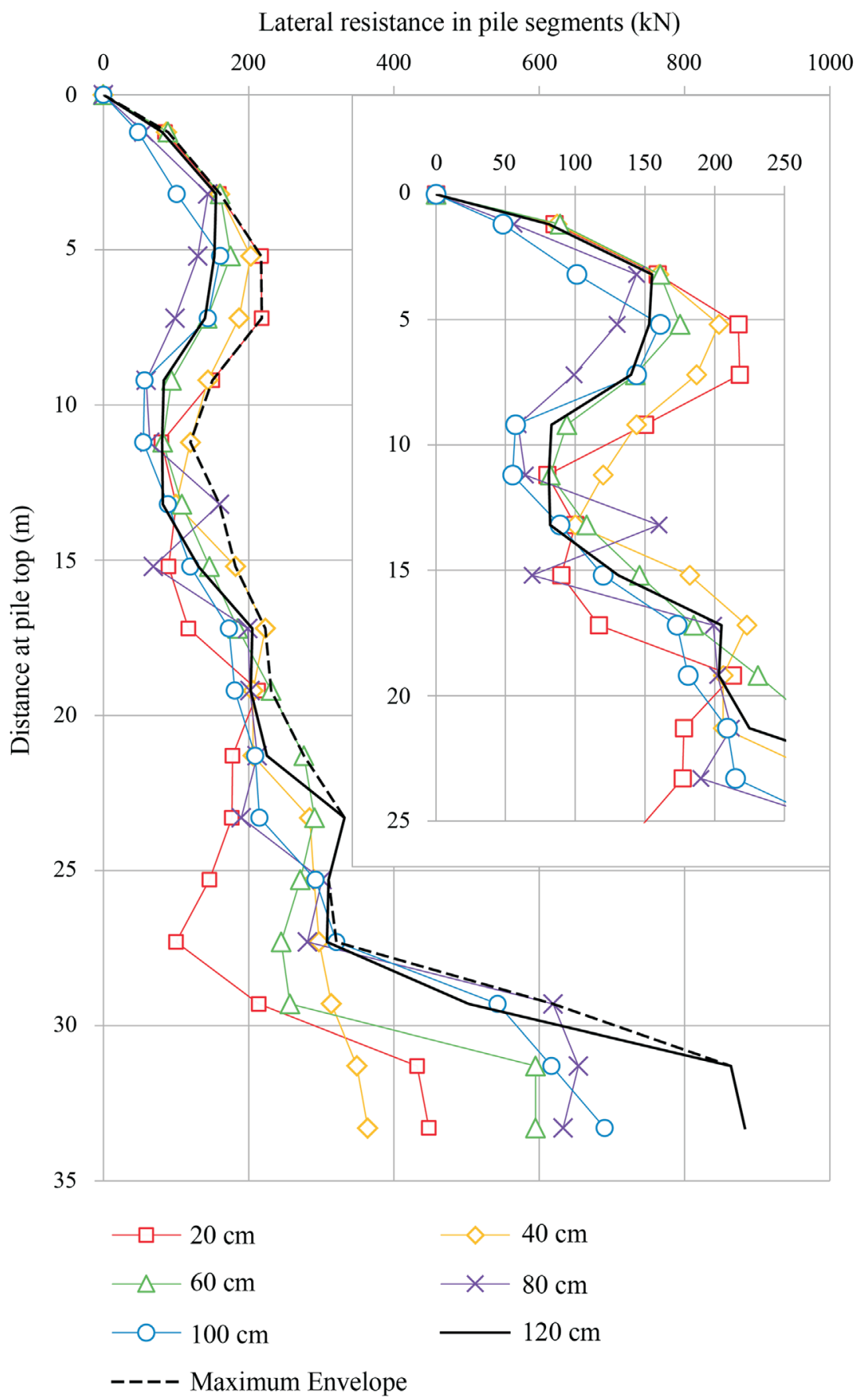

Figure 11 - Lateral resistance distribution - 216 h "set up" time- PC01.

concluded that the applied energy was not enough to activate all lateral resistance. The shaft quake remained constant only within the EOD and the $3 \mathrm{~h}$ rest period. On longer periods, $\mathrm{q}_{\mathrm{s}}$ decreased on segments near the pile toe. Thus, the results obtained for the evaluation of the "set up" can be considered underestimated, mainly in the last segments of the pile-soil system.

A more detailed and accurate evaluation of the skin friction gain can be achieved specifically for the SFL Clay, the predominant soil layer along the pile shaft. According to the soil profile described, this layer lies between depths of $-4.0 \mathrm{~m}$ and $-24.0 \mathrm{~m}$. Another important observation is that the shaft quake remained constant in all rest periods in this depth interval, which indicates that there was maximum skin friction mobilization. Figs, 15 and 16 show the $\mathrm{f} / \mathrm{f}_{0}$ ratio over time only of the SFL Clay layer for both the Maximum Envelope and the blow of $120 \mathrm{~cm}$. The $\mathrm{f}$ and $\mathrm{f}_{0}$ values refer to unit skin friction after a certain period of rest and at the end of driving (EOD), respectively. 


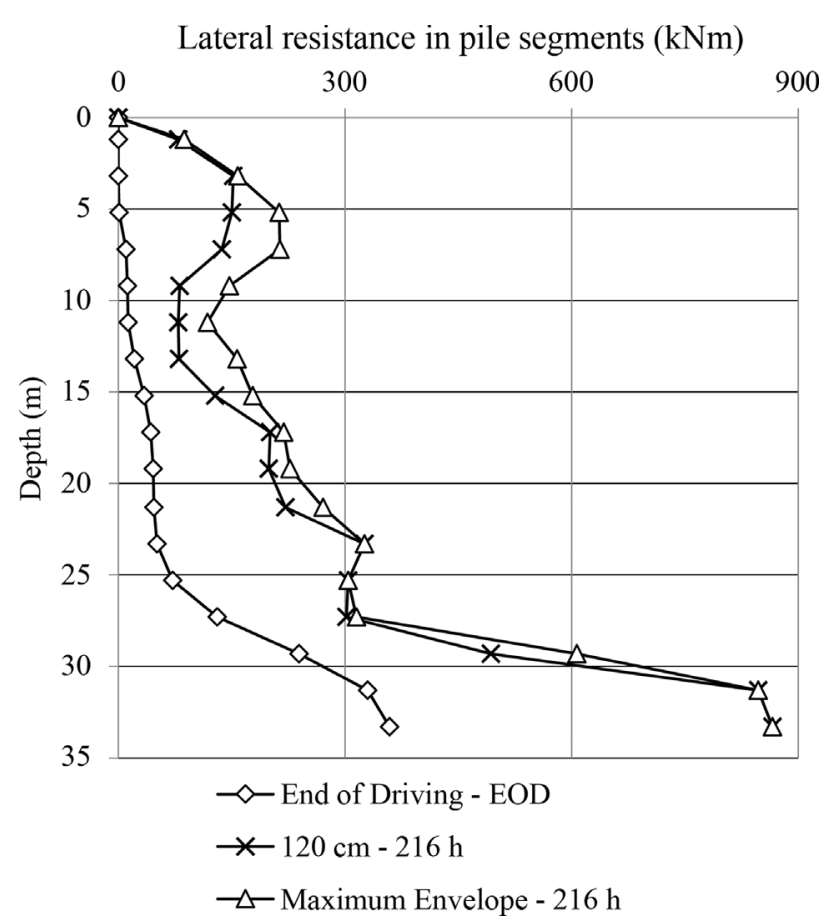

Figure 12 - Lateral resistance distribution -Max. Envelope, EOD and $216 \mathrm{~h}-\mathrm{PC} 01$

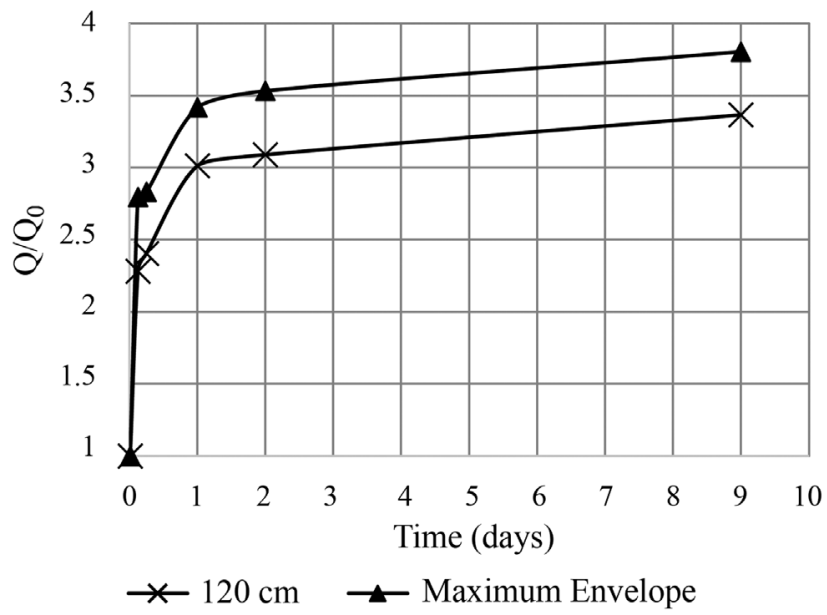

Figure 13 - Results of lateral "set up" - $120 \mathrm{~cm}$ and Maximum Envelope - PC01.

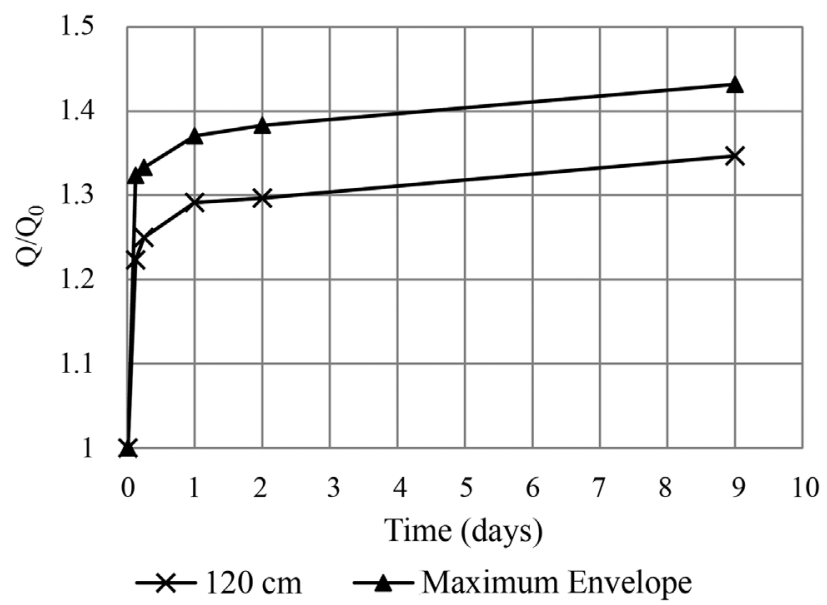

Figure 14 - Results of total "set up" - $120 \mathrm{~cm}$ and Maximum Envelope - PC01.

Based on the results of the Maximum Envelope, it is possible to determine the parameter "A" of Bullock et al. (2005), which depends on the soil type, through the linear regression coefficients obtained in Fig. 15. This analysis shows that for the whole shaft the parameter " $\mathrm{A}$ " is equals to 0.98 and, for the SFL Clay layer alone, 1.6. This difference is due to the fact that the "A" parameter for the entire shaft includes "set up" of deep sandy layers, which have lower "set up" factors. With the same procedure and using only the $120 \mathrm{~cm}$ hammer drop blows, the parameters "A" are smaller compared to those obtained by the Maximum Envelope, as shown in Fig. 16. Among other publications, Bilfinger (2010) obtained the parameter "A" equal to 0.61 for skin friction in the Santos Coastal Plain ("Baixada Santista") through dynamic Load Tests.

As an example of total lateral resistance "set up", Figs. 15 and 16 show that the $\mathrm{f} / \mathrm{f}_{0}$ ratio equals 2 in a rest period of $20 \mathrm{~h}$ considering only the blow of $120 \mathrm{~cm}$, whereas through the Maximum Envelope method this same value would be reached in approximately $10 \mathrm{~h}$.

Table 9 - Summary of the results- PC01.

\begin{tabular}{|c|c|c|c|c|c|c|c|c|}
\hline \multirow[t]{3}{*}{ No. } & \multicolumn{4}{|c|}{$120 \mathrm{~cm}$} & \multicolumn{4}{|c|}{ Maximum envelope } \\
\hline & \multicolumn{3}{|c|}{ Resistance } & \multirow{2}{*}{$\begin{array}{c}\text { Quake on } \\
\text { shaft }(\mathrm{mm})\end{array}$} & \multicolumn{3}{|c|}{ Resistance } & \multirow{2}{*}{$\begin{array}{l}\text { Quake on } \\
\text { shaft }(\mathrm{mm})\end{array}$} \\
\hline & Lateral $(\mathrm{kN})$ & Toe $(\mathrm{kN})$ & Total $(\mathrm{kN})$ & & Lateral $(\mathrm{kN})$ & Toe $(\mathrm{kN})$ & Total $(\mathrm{kN})$ & \\
\hline EOD & 1381 & 5717 & 7098 & 5.62 & 1381 & 5717 & 7098 & 5.62 \\
\hline $3 \mathrm{~h}$ & 3149 & 5533 & 8682 & 1.29 & 3860 & 5533 & 9393 & 3.25 \\
\hline $6 \mathrm{~h}$ & 3321 & 5553 & 8874 & 4.03 & 3908 & 5553 & 9461 & 3.47 \\
\hline $24 \mathrm{~h}$ & 4159 & 5009 & 9168 & 3.32 & 4718 & 5009 & 9727 & 2.66 \\
\hline $48 \mathrm{~h}$ & 4265 & 4939 & 9204 & 3.76 & 4877 & 4939 & 9816 & 3.38 \\
\hline $216 \mathrm{~h}$ & 4647 & 4912 & 9559 & 4.22 & 5252 & 4912 & 1016 & 2.99 \\
\hline
\end{tabular}




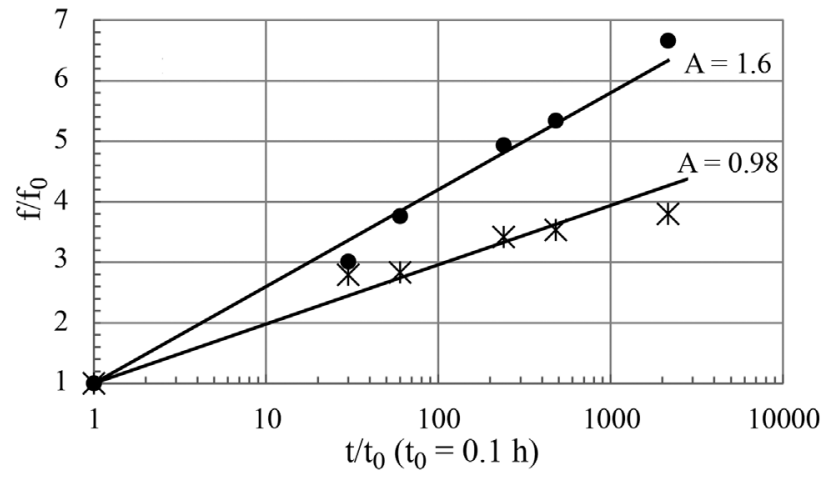

* "Set-up" factor - whole shaft • "Set-up" factor - SFL Clay

Figure 15 - Parameter A - "Set up" lateral factor - Maximum Envelope - PC01.

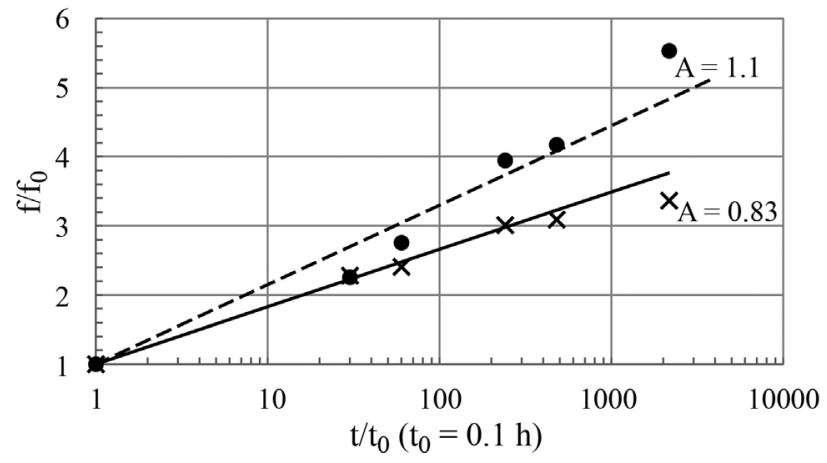

X "Set-up" factor - whole shaft • "Set-up" factor - SFL Clay

Figure 16 - Parameter A - "Set up" lateral - 120 cm - PC01.

\subsection{Coyle-Reese method using the last blow $(120 \mathrm{~cm})$ - $216 \mathrm{~h}$}

The pile was divided into 8 segments, a number higher than the subsoil layers, described above. The unit skin friction values $\mathrm{f}_{\mathrm{s}}$ along the SFL Clay layer varied along depth, in agreement with SPT increasing from 2 to 4. Therefore, this layer was divided into two parts of $10 \mathrm{~m}$ each, as shown in Table 10.
The toe quake is equal to $1.76 \mathrm{~mm}$, the mobilized toe resistance is $4912 \mathrm{kN}$ and the elastic modulus of the pile material is equal to $207 \mathrm{GPa}$. Note, in advance, that the Static Load Test (SLT) was carried out with a pile length of $36.14 \mathrm{~m}$ (see Table 6). Regarding Fig. 17 (a), the pile length was taken as $36.14+2.84 \cong 39 \mathrm{~m}$, in which $2.84 \mathrm{~m}$ is the distance between the PDA sensors and the soil surface. This length was used to calculate the pile elastic shortening on the Coyle-Reese method whose result shows an excellent correlation with the simulated CAPWAP curve, both associated to the last blow $(120 \mathrm{~cm})$ and a "set up" period of 216 h. The comparison between the Coyle-Reese curve with the Static Load Test (SLT) can be made through Fig. 17 (b). In this case, the pile length was taken equal to $36.14 \mathrm{~m}$ (see Table 6) and the small variation between both curves occurs mainly due to the "set up" period in which each test was performed, with a difference of 90 days.

\subsection{Coyle-Reese method using the Maximum Envelope of Lateral Resistance - $216 \mathrm{~h}$}

The data of the load transfer functions given by the Maximum Envelope are shown in Table 11 and the resulting curve of the Coyle-Reese method is shown in Fig. 18.

Figure 18 shows remarkable correlation between the curves simulated by Coyle-Reese method and provided by the Static Load Test (SLT). The total capacity, estimated at $10164 \mathrm{kN}$ by the Coyle-Reese method is indicated by the vertical dashed line. This is exactly the same value calculated by the Maximum Envelope for the 216-h rest period.

As the "set up" time increases, the toe mobilized resistances decrease. Therefore, the simulated curve by CAPWAP $(120 \mathrm{~cm}$ and $216 \mathrm{~h})$ incorporated the lowest mobilization of toe resistance, indicated as $4912 \mathrm{kN}$ in Table 8 . In the context of the Maximum Envelope Method, stated above, a new simulated curve by the Coyle-Reese method was done and shown in Fig. 19 considering the highest mobilization of toe resistance of $5717 \mathrm{kN}$ (Table 8) with a quake of $3.1 \mathrm{~mm}$, both values calculated at the end of driving (EOD). The excellent correlation is maintained and,

Table 10 - Input data for the Coyle-Reese Method - $120 \mathrm{~cm}$ - PC01.

\begin{tabular}{lccccc}
\hline No. & Soil layer & $\Delta \mathrm{H}(\mathrm{m})$ & $\mathrm{f}_{\max }(\mathrm{kPa})$ & $\mathrm{y}_{\mathrm{n}}(\mathrm{mm})$ & $\mathrm{B}=\mathrm{f}_{\max } / \mathrm{y}_{\mathrm{n}}(\mathrm{kPa} / \mathrm{mm})$ \\
\hline 1 & Sand earthwork & 1.3 & 23.5 & 5.73 & 4.1 \\
2 & Clayey sand & 2 & 26.4 & 5.73 & 4.6 \\
3 & Organic Clay (SFL) & 10 & 18.3 & 5.73 & 3.2 \\
4 & Organic Clay (SFL) & 10 & 37.3 & 5.73 & 6.5 \\
5 & Clayey sand (SFL) & 4 & 52.6 & 5.10 & 10.3 \\
6 & Coarse sand & 2 & 85.5 & 3.90 & 21.9 \\
7 & Silty sand & 2 & 147.0 & 3.00 & 49.0 \\
8 & Sandy silt & 2 & 150.2 & 2.10 & 71.5 \\
\hline
\end{tabular}




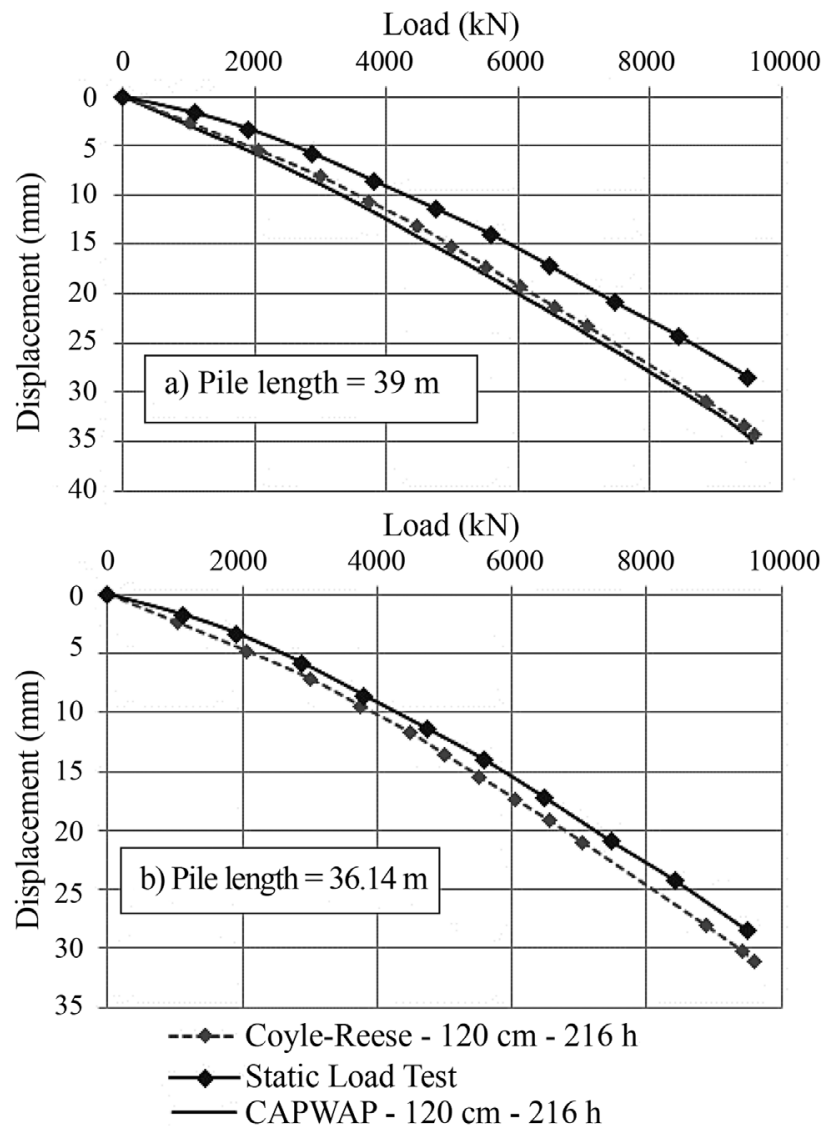

Figure 17 - Simulated load set curves vs. Static Load Test -PC01.

furthermore, the total capacity increased from $10164 \mathrm{kN}$ to $10969 \mathrm{kN}$, as indicated by the vertical dashed line.

\subsection{Summary of the results on static resistances - PC01}

Table 12 summarizes the results obtained for the second case, related to mobilized static resistances. Based on these results, it is concluded that lateral resistance estimated by the Maximum Envelope associated with the Coyle-Reese Method is higher than that given solely by the CAPWAP of the last blow; the difference is 5252 $4647=605 \mathrm{kN}$. Moreover, as shown above, it was possi- ble to obtain a simulation of the load-settlement curve of

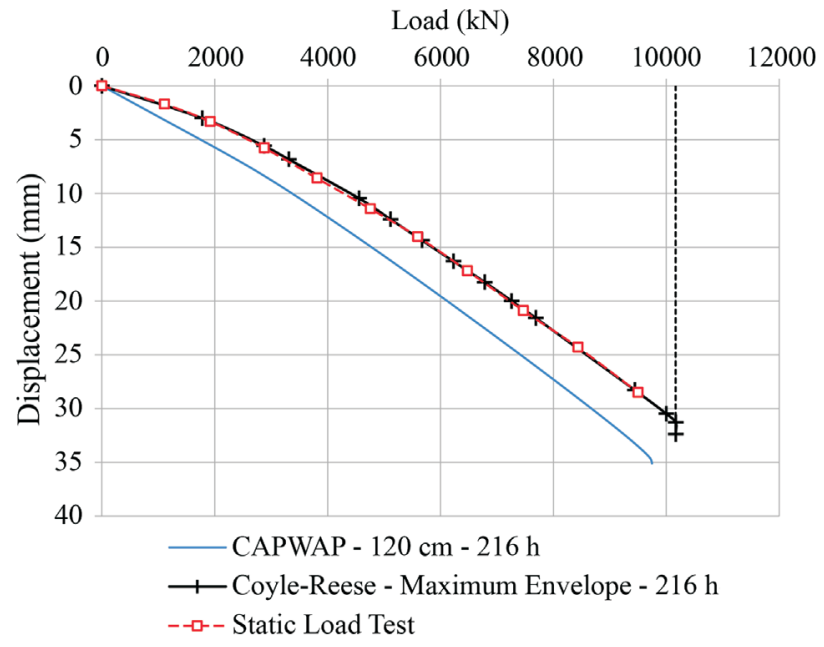

Figure 18 - Simulated load set curves vs. Static Load Test - PC01.

the pile top that approaches very well the Static Load Test (SLT) curve.

\section{Conclusions}

The application of CAPWAP only to the last blow of a dynamic increasing energy test underestimated the maximum mobilized capacity and the resistance distribution along the shaft, particularly in soils with high sensitivity, as was shown in the two studied cases. Initial blows can change the properties of the soil. This behavior is clearly seen in the curve of the lateral skin friction $v s$. displacement of the SFL Clay layer, shown in the first case study. The Maximum Envelope of Lateral Resistance made it possible to recover the lateral skin friction information lost in blows prior to that with maximum applied energy.

Compared to the load-settlement curve obtained in the Static Load Test (SLT), a set of simulated CAPWAP static curves involving all blows in the first case, like a cyclic test, revealed an equal to or better correlation than the

Table 11 - Input data for the Coyle-Reese method - Maximum Envelope - PC01

\begin{tabular}{lccccc}
\hline No. & Soil layer & $\Delta \mathrm{H}(\mathrm{m})$ & $\mathrm{f}_{\text {max }}(\mathrm{kPa})$ & $\mathrm{y}_{\mathrm{n}}(\mathrm{mm})$ & $\mathrm{B}=\mathrm{f}_{\max } / \mathrm{y}_{\mathrm{n}}(\mathrm{kPa} / \mathrm{mm})$ \\
\hline 1 & Sand earthwork & 2 & 25.9 & 5.10 & 5.1 \\
2 & Clayey sand & 2 & 27.3 & 5.10 & 5.3 \\
3 & Organic Clay (SFL) & 10 & 29.5 & 2.68 & 11.0 \\
4 & Organic Clay (SFL) & 10 & 42.2 & 4.65 & 9.1 \\
5 & Clayey sand (SFL) & 4 & 53.4 & 4.36 & 12.3 \\
6 & Coarse sand & 2 & 105.3 & 3.07 & 34.3 \\
7 & Silty sand & 2 & 147.0 & 3.01 & 48.8 \\
\hline
\end{tabular}


Table 12 - Summary of the results - PC01.

\begin{tabular}{lccc}
\hline Test / Method & & Static resistance $(\mathrm{kN})$ & Total \\
\cline { 2 - 4 } & Lateral & Toe & 9497 \\
Static Load Test (SLT) & - & 4912 & 9559 \\
CAPWAP - $120 \mathrm{~cm}-216 \mathrm{~h}$ & 4647 & 4912 & 9596 \\
Coyle-Reese -120 cm - 216 h & 4684 & 4912 & 10164 \\
Maximum envelope - 216 h & 5252 & 4912 & 10164 \\
Coyle-Reese - Maximum envelope - 216 h & 5252 & 5717 & 10969 \\
Maximum Envelope - EOD Toe Resistance & 5252 & 5717 & 10969 \\
Coyle-Reese - Maximum envelope - EOD Toe & 5252 & & \\
\hline
\end{tabular}

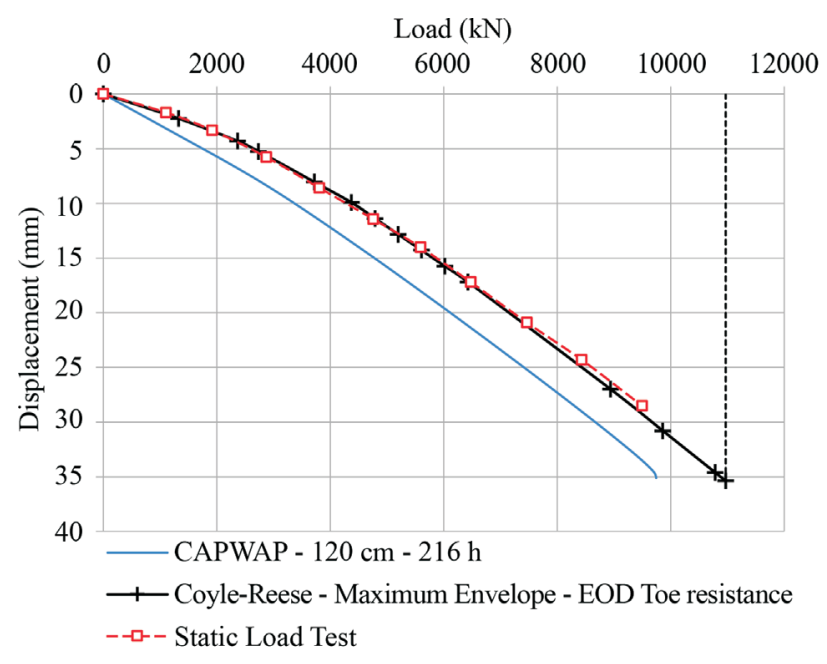

Figure 19 - Simulated load set curves vs. Static Load Test - PC01.

single CAPWAP simulated curve of the last blow, with the greater hammer drop height.

Moreover, the maximum lateral friction values calculated by the Maximum Envelope Method allowed the estimation of the load transfer functions for each soil layer, leading to successful applications of the Coyle-Reese Method. The load-set curves in the 2 studied cases correlated very well with the Static Load Tests (SLT). Such correlations were better in comparison with the simulated CAPWAP static analysis for only one signal, with the maximum applied energy.

The Maximum Envelope of Lateral Resistance performed in several rest periods allowed an assessment of the skin friction development over time for the second studied case. It was possible to calculate the lateral and total "set ups", particularly for the SFL Clay layer. The parameter A of Bullock et al. was figured out, allowing the forecast of skin friction increases on long term for the SFL Clay of Santos Coastal Plain ("Baixada Santista”).

\section{Acknowledgments}

The authors acknowledge the support given by EPUSP - Escola Politécnica of University of São Paulo and would like to thank the companies PDI Engenharia and PDI-USA, for the assistance and for releasing data used in this paper, in particular to Sergio Valverde, Garland Likins and Frank Rausche.

\section{References}

ABNT (2006). Piles - Static Load Test, NBR 12131, Rio de Janeiro, Brazil (in Portuguese).

Aoki, N. (1997). The evaluation of the ultimate bearing capacity of driven piles by using increasing energy dynamic load tests. PhD thesis. Escola de Engenharia de São Carlos. Universidade de São Paulo, São Carlos.

Bilfinger, W. (2010). Set up on driven piles. Proc. V Congresso Luso Brasileiro de Geotecnia, v. 1, pp. 9-29.

Bullock, P.J.; Schmertmann, J.H. \& McVay, M.C. (2005). Side shear setup. I: Test piles driven in Florida. ASCE Journal of Geotechnical Engineering, 131:292-300.

Coyle, H.M.; Reese, L.C. (1966). Load transfer for axially loaded piles in clay. Journal of Soil mech. and foundation division. Procedures of the ASCE: 1-26.

Lydon, F.D. \& Balendran, R.V. (1986). Some observations on elastic properties of plain concrete. Cement and concrete research 16(3):267-459.

Massad, F. (2009). Solos Marinhos da Baixada Santista Características e Propriedades Geotécnicas. Editora de Textos, São Paulo.

Pile Dynamics, Inc. (2006). Case Pile Wave Analysis Program - CAPWAP Manual.

Rausche, F.; Likins, G.; Liang, L. \& Hussein, M. (2010). Static and dynamic models for CAPWAP signal matching. The art of foundation engineering practice. Geotechnical Special Publication, 198:534-553.

Rausche, F.; Hussein, M.; Likins, G. \& Thendean, G. (1994). Static pile load-movement from dynamic measurements. Proceedings of Settlement'94. Vertical and horizontal deformations of foundations and embankments. College Station: 291-302. 
Smith, E.A.L. (1960). Pile driving analysis by the wave equation. Journal of Soil Mechanics and Foundation Division, ASCE 86.

\section{List of symbols}

A: Bullock's constant, dependent on soil type

B: Coyle and Reese's elastic slope

DIET: Dynamic Increasing Energy Test

$\mathrm{f}_{\text {max }}$ : Coyle and Reese's maximum element skin friction

$\mathrm{f}_{\mathrm{s}}$ : CAPWAP's element skin friction

Q: Capacity, dependent on time

$\mathrm{Q}_{\mathrm{p}}$ : Coyle and Reese's toe resistance

$\mathrm{q}_{\mathrm{t}}$ : Toe quake $\mathrm{q}_{\mathrm{tu}}$ : Unloading toe quake

$\mathrm{q}_{\mathrm{u}}$ : Unloading quake

$\mathrm{R}_{\mathrm{lt}}$ : Reload level

$\mathrm{R}_{\mathrm{nu}}$ : Negative ultimate resistance level

$\mathrm{R}_{\mathrm{st}}$ : Toe static resistance

$\mathrm{R}_{\mathrm{ut}}$ : Maximum pile toe element resistance

SLT: Static Load Test

$\mathrm{t}_{\mathrm{g}}$ : Resistance Toe Gap

$\mathrm{U}_{\mathrm{n}}$ : Unloading multiplier

$\mathrm{u}_{\mathrm{px}}$ : Maximum element displacement

$\mathrm{u}_{\mathrm{t}}$ : Maximum pile toe displacement

$\mathrm{y}_{\mathrm{n}}$ : Coyle and Reese's element displacement

$\mathrm{y}_{\mathrm{t}}$ : Coyle and Reese's pile toe displacement 